\title{
Energy Development and Energy Policy in Developing Countries in the Context of Globalization
}

\author{
O. Yu. Yatsenko ${ }^{1}, E$. B. Bespyatova ${ }^{2}, V . L$. Danoyan $^{2}$, V.V.Efremenko ${ }^{2}$ \\ ${ }^{1}$ The State University of Management (GUU), Moscow, Russia \\ ${ }^{2}$ Russian Technological University RTU-MIREA, Moscow, Russia
}

\begin{abstract}
The article is devoted to the problem of the development of independent electric power systems in elaborating countries under the conditions of growing power stuff deficit. Economic and electric-power policy that aids to active consumers' and independent manufacturers' formation at the world market of power manufacturing is the subject of the investigation. A separate section is devoted to the reviewing of the technologies of energy and the scientific potential of the countries, their ability to form the power agenda independently and rationally on the basis of their own stuff, technology and science resources.
\end{abstract}

Index terms. energy development, economic parameters, political parameters, social parameters, energy index.

\section{INTRODUCTION}

The modern state of the world economy is being traditionally defined by the level of technologic development of leading world powers. Till the recent time they were being regarded as the Great Seven countries. The new decade is beginning with the fact that countries of Asia are becoming an economic and manufacturing base and that Chinese People's Republic is the economy leader. China crowded the USA from the leadership position, and meanwhile that country is not as technologically and economically developed as the traditional world leaders. Thus, we have a tendency of the most populated, not owning till a certain time its own industry and an opportunity to develop economically at the expense of its own stuff and lowly effective power bases country's ability not just to work up the necessary economic programs, but also to realize them successfully. This phenomenon lets pay a greater attention to the conditions which the majority of the countries called the "third world" ones has. We introduce the category of a "power index", that is some parameters of economic, social and political state of developing countries letting the realization of a country's energetics functional, energy manufacturing growth opportunity and energy issuing from a population number, economy structure, ecologic and other society-faced challenges need analysis.

The category of a "power index" is conventional and lets the formulating of the project of energetics development not only for a developing or a developed country, but - with using synergetic principles evaluating the opportunities and the potential of energetics development from the point of view of prospects and orienting in a society's progress, the life's quality and level which are desirable for the citizens of states, as well. For this reason, it is necessary to include economic, social and political parameters as elements giving content filling in the term. It lets systematical projecting of the development of energetics as the fundamental of any economic system, watching which way and on what level the development of energetic influences the realization of social programs' fulfillment plans. And finally, political aspects must be the obligatory block of elements of the "power index" just political will being translated via certain foreign- and domestic policy actions, having got a reflection in mass-media and putting a straight and an indirect impact upon public opinion/s formation as the expression of the interests of either strata of a society are in fact the assets which are capable to organize public comprehension in the way that people taking certain economic and social distribution costs into consideration might understand that the problem of a more remote prospect looked sanguine. The successfulness of electric-power projects, as practice is showing, depends not only on owning hydrocarbons, but considerably on correct and up-to-date political decisions taken by a country/s government, as well. And they in their turn should not be situational, sporadic, depending exclusively on a voluntary concurrence of circumstances, the competence and the engagement of political elites. The sustainability of a society's development that depends on the growth of economy becomes probable just under the conditions of stable program measures which are being realized in the energetics sector. So we shall view upon economic, social and political components of the "power index" in more detail.

\section{ECONOMIC PARAMETERS}

It is impossible to give characteristics to the modern state of economy without taking the circumstances that for the

\footnotetext{
*Corresponding author: yatsenkoox@mail.ru
} 
space of almost four decades it can be explained from the position of a regional, global or a separate domestic crisis into consideration. In other words, the state of a pre- postor crisis at simple is the curtained and certifying element characterizing the world economy. Thus instability is becoming a peculiar "stable: marker of any economy, the reasons and the ways of overcoming the situations of crisis will have specific properties conditioned by the formed economic structure and existing within a certain socio-cultural paradigm in each country. The aims for which the power potential of the country is being spent are stable indicators of processes, that take place as a realization of the political will of state leaders, as well. If we take the state of local, regional and global energetics as basis for economic analysis, then this factor has the properties of such kind of coefficient that lets evaluating the "health" of economy, the sustainability and stable growth of social commonwealth and capable political guidance objectively.

The traditionally accepted division of countries into advanced, developed ones and the so called countries of the "third world" will not coincide with the proposed evaluation system. Not every country is far from being deprived of considerable stores of energy-bearers, not every country is far from instability of its access to energy sources. Not every country is far from possessing its electric-power dependence, an opposite to which will include energy resources, energetics systems, sciencetechnique potential for evolutionary development and the preserving of production quality and its consumption on a high level as basic components. Safety and socially just access systems in regard to energy as to one of the main economic boons will become not less important factors as well. The autonomousness of energy systems, their financial independence of foreign and domestic players' influence should be regulated by state as far as we are speaking about market economy. Now we'll look upon energetics as the factor conditioning accelerated economy growth on the example of the largest - Chinese and Indian - developing world economies.

India is the country with the population of 1.3 billion. In its modern state it is a nuclear power having high showings of the economy growth and gross inner produce. At the same time, the growth of Indian economy is conditioned by such factor as the deficit of energetics resources. It creates a complex of problems which considerably slow down the improvement of social and economic indices of the country. The prior problem is its energy-bearer dependence, and this restrains the tempos of the producing industrial sector growth. It goes without saying that India has some energy-bearer resources of the coal, oil and gas of its own. But all of them are critically insufficient for the country's economy service. Besides that, the coal sector is working on local stuff of low quality, unable to serve metallurgy, therefore the coal is also being imported from Australia and SAR. Some modern explorers regard a low amount of the energy manufacturing obtaining factors of the industrial development. The country is more than 5 times backward of China in this index. The manufacturing amount of its own energy is comparable with the Iranian one, but the difference in economic potential $s$ of those countries shows how strongly energy, its deficit - to be more distinct - hampers the progress. Undeveloped and weekly equipped energy system is one more critical point in the Indian energetics. To be more correct - the lack of a single energy system and the wear and tear of the nets where they are being run. Energy delivery within the country is remarkable neither through modernity, nor through stability. This creates auxiliary problems in economic misbalance of the development of its states, their division into more up-to-date and backward, agrarian ones is taking place. Differentiation in the level of life and the opportunity of social and professional growth is becoming a concomitant factor. If we remember that the youth below 25 years of age is the basic part of the population of that country - then the energy deficit hampers the production development and creates unemployment. Namely India is the basic supplier of the countries of Arabian Semi-island with laboring migrants.

The matured modernization of electric nets and their unification is a problem that influences the economy of that country. The next point defined by energetics emerges with understanding that not all the energy is used by manufacturing, households and systems of transport. The huge country's population also needs accessible and cheap energy for routine wants. And here we see a very serious situation concerning the accessibility of this comfort. In fact, India is existing in the 20-th century. It was then when the situation of inaccessibility of electricity for rural inhibiters and availability of electrification in large cities was possible. India cannot supply 400 million. of its own population with electricity. And the same number of the country's inhibiters receives electricity with interruptions. [1]

India is one of the leading countries at the world energetics market. But growth possibilities for it take shape in a way that part of energy production is in process at the expense of low-sort local coal that is being badly reflected upon ecology, the country's oil consumption is demonstrating the following particularity: costumed oil is being not utterly used for the energetics of the country. In India manufacturing structure of oil products is well developed. Therefore, more than half of the purchased hydrocarbon stuff is being processed and exported. The remaining part goes for consumption with transport witch has also a low level of energy consumption in comparison with a necessary one. There is a system of railways in the country that is electrified just by $20 \%$. [2]

Atomic and green energetics have a little specific weight: the first one - in the force of expensiveness and protracted building of atomic stations, and the second is recommended as a necessary alternative replying to the conditions of today/s India for satisfying demand. But high cost of producing and serving wind turbines makes them expensive elements; besides that, the production and the cost price of energy don/t give an opportunity to develop this branch.

China is the very basic consumer of power stuff. The prior world economy is a stably growing market of energy consumption. That/s why the reconstruction of stuff sources, reorientation from coal to hydrocarbons and atomic power is one of the most important showings of energy consumption. From the other side, global 
challenges of the last decade led to the decrease of CFR's economy growth and power sector tempos. The factors of the restructure of stuff basis from which energy is being received as well as stable growth of demand for energy from its direct consumer is a concomitant change in its consumption. Energy consumption in China is already growing not that large at the expense of industry but rather at the expense of particularly urban population. Urbanization is the one of the characteristics of modern energy market that demonstrates the change of coal as a source of energy production for more up-to-date ones hydrocarbons - as more ecological and thus safe sources as well as to the stability and plan character of energy consumption, besides the stable demand. The portion of coal consumption in the structure of China's energetics has been stabilized for the last decade, whereas gas consumption shows stable growth and tops economy indices on the whole by the growth tempos.

Uneven regional development is one more problem of the energy system of China. From the economic point of view, the country has four levels of economy conducting - traditional, agrarian, industrial and innovative production. [3] Asymmetry in development is prominent not only for China, but makes up a problem for most of the countries with developing economy. At the time when industrial and urbanite agglomerations being a locomotive of economic development consume energy which is produced at the expense of proceeding carbons, inner regions of the country, the ones with overwhelming agrarian economy, are still using coal for receiving energy, and this points both at available problems and at the power sector growth abilities.

Considerable rises in the population life quality and energy consumption growth in the private sector are particularities of the current period in the development of CPR. Changes in the urbanization of the country influence consumption behavior at the inner market of energybearers with leading to the demand for energy in the private sector. [4]

A power branch development scenario until 2040 is present in China's plan economy. The demand at the inner gas market will make up in CPR about $6 \mathrm{mln}$. cubic meters a year. Adhering to the figures from prognoses China/s government is planning to supply he inner demand for gas by $42 \%$ at the expense of domestic deliveries and 585 correspondingly at the expense of its own excavation. The country is going to export half of gas via pipelines. [5] Atom energetics remains the most perspective scenario for the development of the corresponding sector. In spite of the risks related to stuff import for autonomous stations their long-tie and stable work lets for sure realize economic projects without passing the glance on instable markers of hydrocarbons.

\section{SOCIAL PARAMETERS}

This group of indicators_must contain_elements which let not only take vital long-time demands of a society for energy consumption into consideration, but also connect them with the impact upon economic and political progress aspects. Being worked out half a century ago, the concept of stable social development about a persistent realization of which the world association is constantly enlightening envisages among other things the shortening of consuming unrenewable stuff and energy sources. In the first turn - 'cause they worsen ecologic conditions of a human-being's existence, deprive future generations of the ability to use them. Modern information stage in the development of society for which innovative kinds of both economic and socially oriented activity that is impossible in the lack of energy are typical is one more important circumstance pointing at mutual relation of social projects and energetics. Information technologies in defining the vector of progress for most of modern societies are unimaginable without electric systems feeding hightechnology productions. A considerable number of businesses depend functionally and existentially on energetics resources in financial and service segments. Thus, basic directions of the supplement of social interests under modern conditions of power development may be viewed upon. Being involved in the processes of digitalization and digital technologies, society must elect power parameters one of objective indices of its development.

\section{THE POLITICAL ASPECT}

The Political Aspect of the development of energetics, its defining role formation of long-time geopolitical aims is being quite well acknowledged by political players of today on both global and regional and state levels. Basic directions of Russian geopolitics as socially and economically oriented at the RF needs are set forth in the project "Electric-Power Strategy of Russian Federation for the Period up to 2035". Specifically, "maximum assistance to Russian social-economic development, from one side, and strengthening and tightening positions in world energetics for the period up to 2035 at the minimum, from another, is the aim of Russian energetics". [6, P.6]

The history when electric power became defining in the interests of states begins in the XIX century. S.Yu. Vitte was one of innovators who acknowledged the role and meaning of complex development of separate regions of the Russian Empire. Being the minister of finances, he reported to emperor Alexander the $3 \mathrm{~d}$ of the results of his journey to the north, where he had made a detailed exploration and formed the program of North coping from military and economic points of view.

This program included: creating several administrative centers; coping numerous large and small inhibitory points: setting down big and little ports in comfortable, defended harbors; setting down docks and work-shops for repairing vessels; setting down telegraph lines; building roads, railways in particular. [7, P.47]

Without calling a great enthusiasm within the czar's government this program was an economic and political project the beginning of the realization of which occurred in the 30-s of the XX century and was interrupted by World War II. Full-scale coping of Arctic territories on a constant base became possible just in modern conditions. The interest for this rich in nature resources region is being demonstrated not only by Russia, where it has a status of a national project, but also by Scandinavian and North-American countries, which see a resource base for 
the development of their own region in coping Arctic riches. [7]

The realization of programs for the coping of Arctic territories is possible only with an availability of a highcapacity power base that becomes one of the main conditions of bringing the plan to life in the severe climate of the North. Coal and diesel fuel as the single source of energy supplement were for a long time restraining and making unremunerative any projects on Arctic. The first SAE-PS "Academician Lomonosov" changed the situation. Political interests of the country, which it had always been having in this region, obtained a reliable basis for their realization. And also the fact that atom energetics applies to all the modern economic and ecologic criterion of the creation of favorable economy conducting activity is its merit. Competition of countries on the Arctic shelf is obtaining a real basis, besides political statements, and our country becomes the flagman of this process. Thus, when speaking about energetics indicators of policy, one may objectively proceed from them while estimating the satisfaction of inner market needs as well as the influence on the world market, social processes and politics.

\section{REFERENCES}

1. G.O Khalova., A.R Reva. Modern State and Prospects of India's Oil-Gas Complex Development. Magazine "Innovations and Investments” №7, P.77-80 (2016)

2. A.A. Karpov India as the Participant of the World Energy Market: Trends and Prospects. Magazine "Innovations and Investments №1, P.70-73 (2017)

3. Ye. B Bespyatova., O.Yu. Yatsenko Russia and China: Role and Meaning of the Contribution of Educational and Experts' Association into Innovation Processes/ Russia - China: Social Guidance in the Digital Epoch: Monograph. Moscow, State Management University, P.230 (2020)

4. Ts. Zhen' Analysis of the Impact of CPR upon the Consumption of Primary Energy-Bearers: Magazine "Problems of Economy and Oil-Gas Complex Guidance”. №12, P. 55-57 (2016)

5. V.V. Kostyuk, I.V. Bashkatov Evaluation of the Potential of China's Natural Gas Market Development. "Innovations and Investments". 7,3. P.71. (2018)

6. Web resource: Project "Electric-Power Strategy of Russian Federation for the Period up to 2035"// https://minenergo.gov.ru/node/1920.

7. Yu. N. Zhukov "Stalin: The Arctic Shield" (M.: Vagrius, P.47.,2008)

8. D.S. Boroukhin Problems and Prospects of Carbonless Economy in Arctic Regions. Magazine "SocialEconomic Development: Theory and Practice”. №1 (40), P.13-16. (2020) 